\title{
PENYEDIAAN FASILITAS SANITASI DAN AIR BERSIH BAGI PENGUNGSI KORBAN BENCANA GEMPA DI DUSUN LENDANG RE, KABUPATEN LOMBOK BARAT
}

\author{
PROVIDING SANITATION AND CLEAN WATER FACILITIES FOR EARTHQUAKE \\ DISASTER VICTIMS IN LENDANG RE VILLAGE OF WEST LOMBOK DISTRICT
}

\author{
Dian Puspita Sari ${ }^{*}$, Dewi Suryani, Titi Pambudi Karuniawati, Wahyu Sulistya Affarah, Isna \\ Kusuma Nintyastuti, Deasy Irawati
}

Program Studi Pendidikan Dokter, Fakultas Kedokteran, Universitas Mataram

Jalan Pendidikan Nomor 37, Kota Mataram, Provinsi NTB, 83115

Alamat korespondensi : dianps@unram.ac.id

(Tanggal Submission: 10 Januari 2020, Tanggal Accepted: 23 April 2020)

\begin{abstract}
ABSTRAK
Gempa besar yang melanda pulau Lombok pada akhir Juli sampai Agustus 2018 telah menyebabkan korban jiwa, korban luka dan kerusakan berbagai sarana dan prasarana serta tempat tinggal. Setelah terjadinya bencana alam apapun jenisnya, kejadian penyakit infeksi umumnya akan meningkat. Hal ini terjadi akibat kerentanan sistem kesehatan di suatu wilayah dan gangguan pemenuhan kebutuhan dasar seperti air bersih, sanitasi, tempat perlindungan dan pelayanan kesehatan. Meningkatnya jumlah penduduk terdampak yang mengungsi ke pusatpusat evakuasi juga akan meningkatkan kejadian penyakit-penyakit yang berhubungan dengan kepadatan, air bersih, sanitasi dan higiene. Lebih dari itu, masalah ketersediaan air bersih dan sanitasi dapat berdampak pada meningkatnya kejadian stunting yang memiliki dampak kesehatan jangka panjang. Dusun Lendang Re merupakan salah satu wilayah yang terdampak bencana. Lebih dari $90 \%$ rumah hancur dan rusak berat dan sekitar 750 orang warga terpaksa mengungsi. Jumlah toilet darurat yang tersedia belum memenuhi kebutuhan pengungsi dan standar minimal. Hal ini rentan menyebabkan pencemaran lingkungan dan penyebaran penyakit terutama penyakit infeksi. Kegiatan pengabdian pada masyarakat ini bertujuan untuk meningkatkan akses warga pengungsi di Dusun Lendang Re terhadap air bersih dan fasilitas sanitasi. Setelah melakukan survey pendahuluan, mengurus perijinan dan membangun komitmen dengan warga, tim pelaksana kegiatan pengabdian kepada masyarakat membangun dua set fasilitas sanitasi dan penampungan air bersih. Setiap set terdiri dari tiga bilik toilet/kamar mandi dengan jamban jongkok serta satu pelataran cuci dengan keran air. Sumber air bersih berasal dari sumur terdekat yang disalurkan melalui sistem pipa dengan pompa air listrik dan ditampung dalam tandon penampung air di atas menara baja. Komunikasi dan koordinasi yang baik dengan warga dan tokoh masyarakat, pemilihan lokasi dan perijinan penggunaan lahan serta serta kelayakan spesifikasi dan kelengkapan fasilitas yang dibangun mendukung keberlangsungan penggunaan fasilitas ini di lokasi bencana.
\end{abstract}

Kata Kunci: air bersih, gempa bumi, korban bencana gempa, sanitasi 


\section{PENDAHULUAN}

Antara 29 Juli hingga 19 Agustus 2018, empat gempa besar berskala 6.4 samai 7.0 Skala Richter (SR) terjadi di pulau Lombok (BNPB, 2018). Badan Penanggunalangan Bencana Nasional pada tanggal 20 Agustus 2018 melaporkan bahwa runtutan gempa yang terjadi telah menyebabkan 506 korban jiwa, 74.361 rumah hancur atau rusak parah dan 431.416 orang terpaksa mengungsi (BNPB, 2018). Gempa ini juga menyebabkan kerusakan pada fasilitas infrastruktur penting seperti rumah sakit, puskesmas, serta fasilitas air bersih dan sanitasi.Dua kabupaten yang terdampak berat adalah Kabupaten Lombok Utara dan Kabupaten Lombok Timur.

Pemerintah Provinsi NTB telah menetapkan periode respon darurat sejak 5 sampai 25 Agustus 2018. Pada masa ini intervensi segera seperti pencarian dan penyelamatan penyintas, penyediaan layanan medis dan bedah bagi korban luka serta penyediaan tempat pengungsian sementara, makanan dan minuman merupakan prioritas. Memasuki fase pemulihan, prioritas intervensi difokuskan pada pencegahan risiko kesehatan masyarakat.

Setelah terjadinya bencana alam apapun jenisnya, kejadian penyakit infeksi umumnya akan meningkat. Hal ini terjadi akibat kerentanan sistem kesehatan di suatu wilayah dan gangguan pemenuhan kebutuhan dasar seperti air bersih, sanitasi, tempat perlindungan dan pelayanan kesehatan (Salazar et al., 2016). Meskipun pada masa awal pasca gempa umumnya masalah kesehatan yang dihadapi adalah korban jiwa, fraktur tulang dan luka-luka akibat tertimpa reruntuhan bangunan, namun karena meningkatnya jumlah penduduk terdampak yang mengungsi ke pusat-pusat evakuasi, kejadian penyakit-penyakit yang berhubungan dengan kepadatan, air bersih, sanitasi dan higiene dapat meningkat (Salazar et al., 2016). Penyakit-penyakit seperti diare, infeksi kulit, demam tifoid, dan hepatitis $\mathrm{A}$ merupakan ancaman bagi kesehatan pengungsi (WHO, 2010). Suatu kajian sistematik mengenai dampak gempa bumi di Haiti pada tahun 2010 menyimpulkan bahwa penyakit infeksi terutama diare baik kolera dan non-kolera merupakan penyebab utama mortalitas dan morbiditas pada anak-anak (Dube et al., 2017).
Oleh karena itu penyediaan air bersih dan fasilitas sanitasi merupakan langkah penting untuk mencegah terjadinya wabah penyakit infeksi.

Lebih dari sekedar mencegah meningkatnya kasus infeksi yang sekilas tampak seperti akibat jangka pendek, penyediaan air bersih dan fasilitas sanitasi juga penting untuk menjaga bahkan meningkatkan kualitas kesehatan penduduk dalam jangka panjang. Berdasarkan data dari 137 negara di dunia, Danaei et al. (2016) menemukan bahwa faktor lingkungan seperti ketersediaan air bersih dan sanitasi merupakan faktor kedua tertinggi yang berkontribusi terhadap terjadinya stunting secara global setelah restriksi pertumbuhan janin dalam kandungan. Stunting adalah gangguan pertumbuhan linear (panjang atau tinggi badan) pada fase awal kehidupan yang mengakibatkan kegagalan mencapai potensi tinggi badan genetik di masa dewasa (Vilcins, Sly \& Jagals, 2018). Seorang anak disebut mengalami stunting apabila tinggi badan untuk usianya berada dua standar deviasi di bawah nilai median Standar Pertumbuhan Anak dari WHO untuk kelompok usia dan jenis kelamin yang sama (de Onis \& Branca, 2016). Stunting tidak hanya memengaruhi pertumbuhan fisik, tetapi juga menghambat perkembangan neurokognitif seseorang dan meningkatkan risiko mengalami penyakit kronis di masa dewasa (de Onis \& Branca, 2016). Berdasarkan data WHO pada tahun 2018, prevalensi stunting pada anak di bawah usia lima tahun (balita) secara global adalah 22\%, sementara hasil Riset Kesehatan Dasar (RISKESDAS) tahun 2018 menemukan bahwa 30.8\% balita di Indonesia mengalami stunting. Provinsi Nusa Tenggara Barat adalah salah satu penyumbang balita stunting tertinggi di Indonesia dengan prevalensi sebesar 33 \% (Badan Penelitian dan Pengembangan Kesehatan Kementerian Kesehatan RI, 2018). Oleh karena itu, bencana gempa bumi yang melanda pulau Lombok di tahun 2018 tidak hanya akan berdampak pada kondisi kesehatan masyarakat pada saat itu, tetapi dapat berdampak jangka panjang apabila tidak dilakukan upaya untuk memastikan ketersediaan air bersih dan fasilitas sanitasi bagi masyarakat yang terdampak oleh bencana ini.

Meskipun air bersih telah didistribusikan ke penampungan-penampungan air di lokasi pengungsian oleh Palang Merah Indonesia, namun fasilitas sanitasi seperti toilet masih terbatas, terutama di kabupaten Lombok Barat. Penyediaan 
toilet sementara di awal fase pemulihan masih terfokus di kabupaten Lombok Utara dan akan memerlukan waktu untuk mencakup area terdampak lainnya. Berdasarkan survey pendahuluan yang dilakukan tim, warga pengungsi gempa di beberapa tempat di Lombok Barat seperti di desa Selat, kecamatan Narmada dan dusun Guntur Macan, kecamatan Gunung Sari menggunakan air sungai untuk mandi, mencuci dan buang air. Hal ini dapat meningkatkan pencemaran lingkungan, risiko penularan penyakit dan masalah gizi pada balita seperti stunting. Kegiatan pengabdian kepada masyarakat ini bertujuan untuk meningkatkan akses warga pengungsi di Dusun Lendang Re, Kecamatan Batu Layar, Kabupaten Lombok Barat terhadap air bersih dan fasilitas sanitasi berupa toilet, kamar mandi dan tempat cuci.

\section{METODE KEGIATAN}

Kegiatan ini dilaksanakan dalam beberapa tahapan. Pada tahap persiapan, tim pengabdian melakukan survey lokasi, mengurus perijinan, dan membangun komitmen dengan warga. Survey bertujuan untuk mengetahui jumlah pengungsi, menilai kebutuhan fasilitas sanitasi, menilai ketersediaan dan luas lahan untuk pembangunan fasilitas sanitasi, mengetahui keberadaan sumber air bersih, menilai akses transportasi untuk penyaluran bahan-bahan, serta menilai potensi partisipasi warga dalam kegiatan. Survey dilakukan pada tanggal 18 Agustus 2018. Berdasarkan survey langsung ke posko pengungsian di dusun Lendang Re, desa Lembah Sari, kecamatan Batu Layar, kabupaten Lombok Barat, lebih dari 90\% rumah hancur dan rusak berat. Di lokasi ini tim pengabdian bertemu dengan Bapak Amul, kader posyandu setempat yang juga membantu memberikan data pengungsi serta menunjukkan lokasi-lokasi pengungsi dan fasilitas sanitasi yang ada.

Dalam menentukan spesifikasi fasilitas sanitasi bagi warga pengungsi, beberapa aspek yang dipertimbangkan oleh tim pengabdian adalah: (1) memenuhi kriteria fasilitas sanitasi yang baik menurut WHO yaitu adanya pembatasan kontak antara ekskreta (kotoran) dengan manusia, (2) dapat dikerjakan oleh tenaga lokal, (3) menggunakan bahan yang mudah diperoleh dan tahan lama, (4) sesuai dengan budaya lokal, dan (5) dapat terus digunakan setelah masa tanggap darurat selesai.

Berdasarkan pertimbangan di atas, fasilitas sanitasi yang dibangun memiliki spesifikasi sebagai berikut: (1) menggunakan pondasi yang lebih tinggi dari permukaan tanah di sekitarnya, (2) lantai terbuat dari semen, (3) memiliki satu jamban keramik jongkok untuk setiap ruang toilet, (3) memiliki rangka dinding dari baja atau baja ringan, (4) menggunakan pintu dan atap dari bahan spandek, (5) disediakan satu keran dan ember air untuk setiap ruangan toilet, serta (6) septic tank kedap air dengan jarak minimal $10 \mathrm{~m}$ dari sumber air (sumur terlindung). Sumber air untuk fasilitas sanitasi diambil dari sumur terdekat menggunakan pompa listrik yang disalurkan melalui sistem pipa dan disediakan tandon untuk menampung air. Jumlah fasilitas sanitasi yang dibangun terutama bergantung pada ketersediaan lahan, namun diupayakan agar pada setiap lokasi dibangun setidaknya tiga kamar mandi masing-masing dengan jamban dan satu tempat cuci.

Pembangunan fasilitas sanitasi dilakukan oleh tim pelaksana teknis yang ditunjuk oleh tim pengabdian bekerja sama dengan warga setempat. Sebelum pembangunan, tim teknis telah mendapatkan pengarahan mengenai spesifikasi kamar mandi/tempat cuci serta telah diperkenalkan kepada warga setempat.

\section{HASIL DAN PEMBAHASAN}

Di Dusun Lendang Re pengungsi gempa berjumlah 164 kepala keluarga (KK) dengan total pengungsi 750 jiwa. Seratus KK mengungsi di tenda-tenda di tengah sawah dan 64 KK sisanya mengungsi di tanah kebun yang berada di belakang perkampungan yang hancur untuk menjaga kandang sapi mereka. Dua minggu pasca gempa hanya terdapat enam buah toilet sementara dan empat di antaranya masih dalam pembangunan. Tersedia pula tiga buah penampung air berukuran 1000 liter yang disuplai oleh Palang Merah Indonesia setiap satu sampai dua hari sekali. Seluruh toilet dan tempat penampungan air berlokasi pada lokasi pengungsian utama yang berada di tengah sawah, sementara pengungsi yang berada di kebun harus berjalan kaki sekitar 300 meter untuk mengakses toilet sementara. Ada pula warga yang masih memanfaatkan toilet di rumah-rumah yang rusak dengan risiko tertimpa 
bagian rumah yang runtuh. Jika ditinjau dari kecukupan jumlah serta jarak tempuh untuk mengakses toilet, kondisi ini jauh dari Standar Minimal Penanggulangan Masalah Kesehatan Akibat Bencana dan Penanganan Pengungsi yang ditetapkan melalui Keputusan Menteri Kesehatan Republik Indonesia Nomor 1357 tahun 2001 (Kemenkes RI, 2001). Berdasarkan standar ini, jarak jamban tidak boleh lebih dari 50 meter dari pemukiman pengungsi atau lebih dari 1 menit berjalan kaki, dan tiap jamban digunakan paling banyak oleh 20 orang. Berdasarkan analisis situasi, tim pengabdian menawarkan kepada warga untuk membangun fasilitas sanitasi di sekitar kebun agar mudah diakses oleh pengungsi yang berada di sana.

Pembangunan set fasilitas sanitasi pertama dilakukan setelah mendapatkan persetujuan pemilik kebun. Dalam berkomunikasi dengan warga pengungsi, tim pengabdian mengidentifikasi tokoh masyarakat yang di lokasi bencana yaitu Bapak Amul, kader posyandu setempat dan kepala Dusun. Setelah menyampaikan maksud dan rencana tim pengabdian kepada kedua tokoh ini, tim pengabdian mempertemukan mereka dengan tim pelaksana teknis yang akan melaksanakan pembangunan. Melalui kedua tokoh ini, persetujuan warga pemilik kebun berhasil didapatkan dan warga bersedia membantu pelaksanaan pembangunan. Set fasilitas sanitasi yang dibangun terdiri atas tiga bilik toilet, masingmasing dengan sebuah jamban jongkok, keran air, ember dan gayung serta satu buah pelataran cuci dengan tiga keran air. Air diperoleh dari sumur terdekat yang dialirkan menggunakan pompa listrik ke tandon penampungan air dan ke keran-keran air. Pompa air listrik, tandon air dan menara tandon juga merupakan bagian dari setiap set fasilitas yang dibangun. Pembangunan set pertama dimulai pada 23 November 2018 dan selesai pada 10 Desember 2018. Setelah set fasilitas sanitasi pertama rampung dan dirasakan manfaatnya oleh warga, warga lainnya menawarkan halaman rumahnya sebagai lokasi pembangunan set fasilitas kedua. Set kedua rampung pada awal Januari 2019.

Ketika dilakukan peninjauan pada bulan Maret 2019, kedua set MCK masih digunakan oleh warga pengungsi sementara toilet darurat lainnya yang sebelumnya dibangun di sekitar sawah di lokasi pengungsian utama sudah dibongkar karena sawah akan ditanami dan warga sudah pindah dari lokasi tersebut. Selain pemilihan lokasi MCK dan persetujuan pemilik tanah, pembangunan menara tandon air dan pemipaan air dari sumur terdekat ke tandon penampung air dan keran-keran MCK juga mendukung keberlangsungan fungsi MCK yang telah dibangun. Warga tidak perlu membawa air sendiri jika hendak menggunakan toilet karena sudah tersedia keran, ember dan gayung. Sifat bangunan yang semi permanen dengan pondasi dilapis semen, rangka baja, dinding dan atap spandek juga sesuai dengan kondisi psikologis warga yang masih khawatir akan konstruksi bangunan dengan tembok batu bata yang hancur karena gempa. Terkait hal ini, atap dan dinding spandek dinilai lebih aman oleh warga.

Meski dimaksudkan untuk mengatasi kebutuhan selama masa pengungsian darurat, MCK yang dilengkapi dengan septic tank kedap air yang berjarak setidaknya 10 meter dari sumber air tanah ini telah memenuhi syarat untuk tetap dapat digunakan pasca bencana. Sekitar 60 - 100 warga korban bencana menggunakan MCK yang telah dibangun ini, yang berarti satu jamban digunakan oleh 10 - 15 warga. Hal ini masih memenuhi standar minimal jumlah jamban untuk masyarakat korban bencana yang mensyaratkan satu jamban paling banyak digunakan oleh 20 orang (Kemenkes RI, 2001). Kegiatan pengabdian berupa pembangunan fasilitas sanitasi di Dusun Lendang Re telah terlaksana berkat kerjasama yang baik dengan warga setempat.

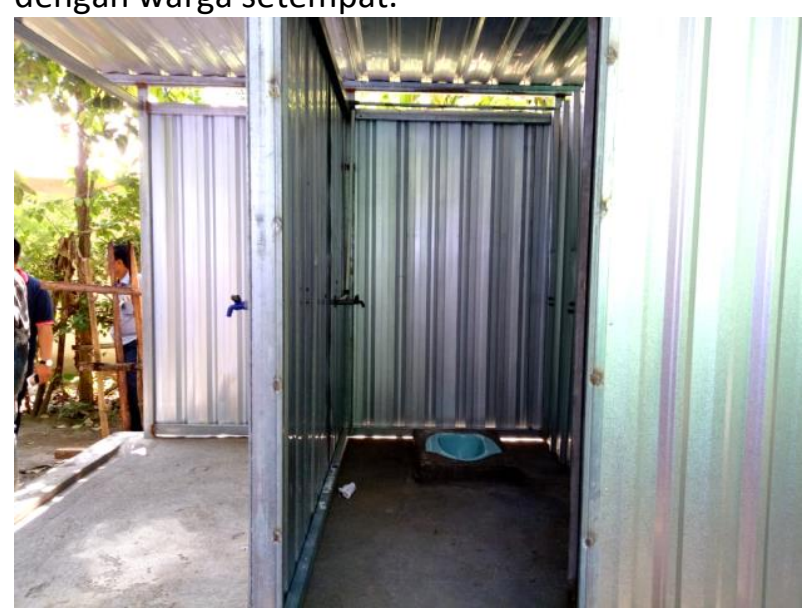

Gambar 1. Set fasilitas sanitasi 1- bilik toilet dan pelataran cuci 


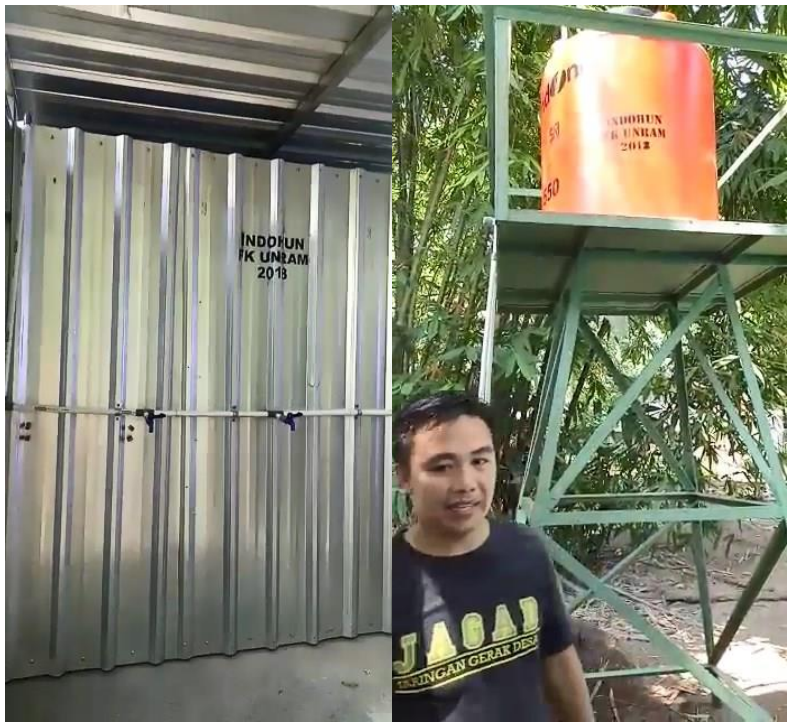

Gambar 2. Set Fasilitas sanitasi 1 - pelataran cuci dan tandon penampung air

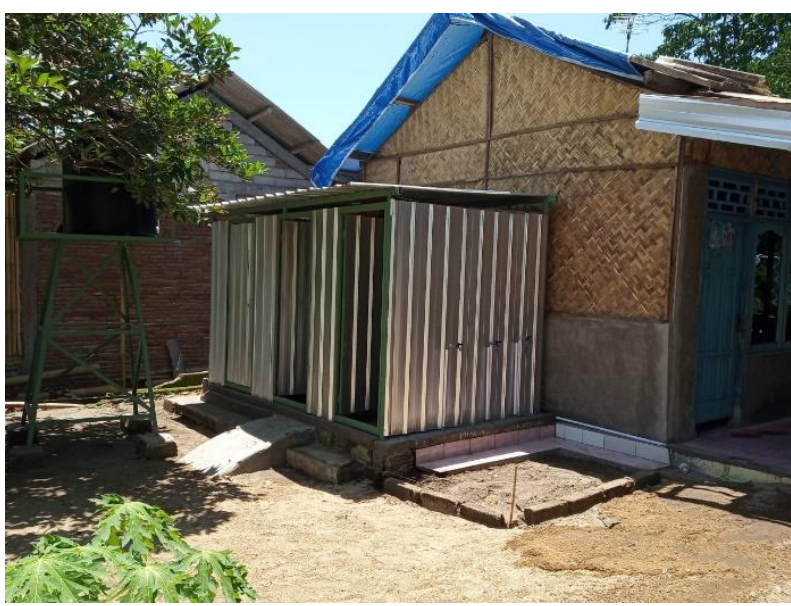

Gambar 3. Set fasilitas sanitasi 2

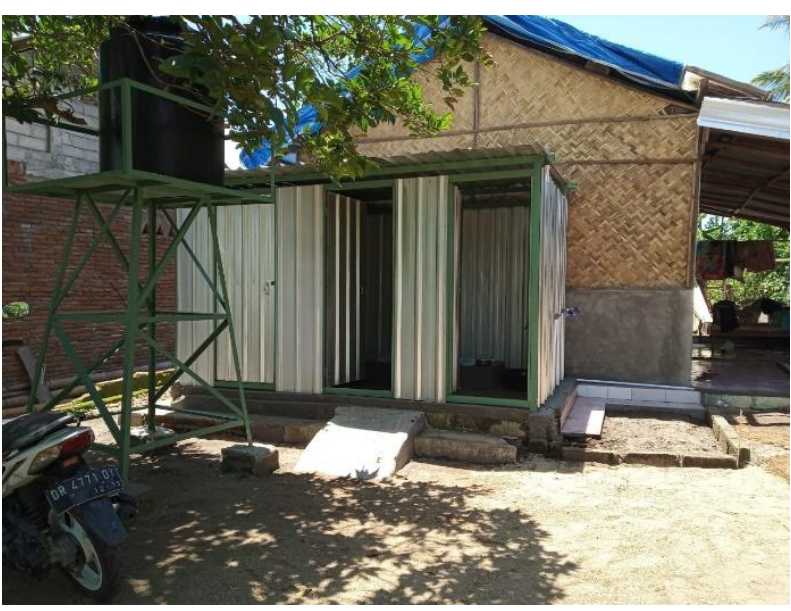

Gambar 4. Set fasilitas sanitasi

\section{KESIMPULAN DAN SARAN}

Kegiatan pengabdian kepada masyarakat ini telah berhasil meningkatkan akses warga pengungsi di Dusun Lendang Re terhadap air bersih dan fasilitas sanitasi. Keberhasilan intervensi kesehatan pada masa tanggap bencana ini perlu dievaluasi dengan melihat prevalensi penyakit infeksi serta prevalensi kasus malnutrisi pada anak seperti stunting, dan membandingkannya dengan masa sebelum terjadinya gempa.

\section{UCAPAN TERIMA KASIH}

Tim pelaksana kegiatan pengabdian kepada masyarakat ini mengucapkan terima kasih kepada Indonesia One Health University Network (INDOHUN) yang telah menyalurkan dana bantuan bagi korban gempa Lombok melalui tim pengabdian, kepada Fakultas Kedokteran Universitas Mataram, Bapak Heru Subaktianto dan Bapak Dawud Budiman, serta warga dusun Lendang Re yang telah mendukung kegiatan ini.

\section{DAFTAR PUSTAKA}

Badan Nasional Penanggulangan Bencana. 2018. Potensi nasional masih mampu mengatasi bencana lombok, tanpa harus menyatakan bencana nasional [online] Available from: https://bnpb.go.id/tanggap-daruratpenanganan-gempa-lombok-berakhirdilanjutkan-transisi-darurat-ke-pemulihan

Badan Penelitian dan Pengembangan Kesehatan Kementerian Kesehatan Republik Indonesia (2018) Hasil utama RISKESDAS 2018.

[Online]. Available from: http://kesmas.kemkes.go.id/assets/upload/ dir_519d41d8cd98f00/files/Hasil-riskesdas2018_1274.pdf

Danaei, G. et al. (2016) Risk Factors for Childhood Stunting in 137 Developing Countries: A Comparative Risk Assessment Analysis at Global, Regional, and Country Levels, PLoS Medicine, 13(11), pp. 1-18. doi: 10.1371/journal.pmed.1002164.

de Onis, M. and Branca, F. (2016) 'Childhood stunting: A global perspective', Maternal and Child Nutrition, 12, pp. 12-26. doi: $10.1111 / \mathrm{mcn} .12231$. 
Dube, A., Moffat, M., Davison, C., \& Bartels, S. 2017. Health outcomes for children in Haiti since the 2010 earthquake: A systematic review. Prehospital and Disaster Medicine, 33 (1), pp. 77-88, doi:10.1017/S1049023X17007105

Kementerian Kesehatan RI. 2001. Keputusan Menteri Kesehatan Republik Indonesia Nomor 1357/Menkes/SK/XII/2001 tentang Standar Minimal Penanggulangan Masalah Kesehatan Akibat Bencana dan Penanganan Pengungsi.

Salazar, M.A., Pesigan, A., Law, R., \& Winkler, V. 2016. Post-disaster health impact of natural hazards in the Philliphines in 2013. Global Health Action, 9, http://dx.doi.org/10.3402/gha.v9.31320

Vilcins, D., Sly, P. D. and Jagals, P. 2018. 'Environmental risk factors associated with child stunting: A systematic review of the literature', Annals of Global Health, 84(4), pp. 551-562. doi: 10.29024/aogh.2361.

World Health Organization. 2010. Public health risks assessment and intervention earthquake: Haiti. [online] Available from: http://apps.who.int/iris/bitstream/handle/1 0665/70221/WHO_HSE_GAR_DCE_2010.1_ eng.pdf?sequence $=1$ 